\title{
Neglecting irrigation contributes to the simulated summertime warm-and-dry bias in the central United States
}

\author{
Yun Qian $\mathbb{1}^{1 凶}$, Zhao Yang ${ }^{1}$, Zhe Feng $\mathbb{1}^{1}$, Ying Liu $\mathbb{C}^{1}$, William I. Gustafson Jr. $\mathbb{D}^{1}$, Larry K. Berg $\mathbb{1}^{1}$, Maoyi Huang ${ }^{1}$, Ben Yang $\mathbb{1}^{2}$ and \\ Hsi-Yen $\mathrm{Ma}^{3}$
}

A vast number of weather forecast and climate models have a common warm-and-dry bias, accompanied by the underestimation of evapotranspiration and overestimation of surface net radiation, over the central United States during boreal summer. Various theories have been proposed to explain these biases, but no studies have linked the biases with the missing representation of human perturbations, such as irrigation. Here we argue that neglecting the impact of irrigation contributes to the longstanding warm surface temperature and lack of precipitation biases over this region. By using convection-permitting multi-season simulations over the contiguous United States coupled with an operational-like irrigation scheme, we show that irrigation increases surface evapotranspiration and decreases surface temperature by increasing evaporative fraction. By increasing the frequency of mesoscale convective systems, irrigation reduces the summertime model precipitation deficit and improves the simulated precipitation diurnal cycle over the Great Plains. The increased precipitation also alleviates the warm bias in our simulation setup, likely by damping the positive feedback between soil moisture and temperature.

npj Climate and Atmospheric Science (2020)3:31 ; https://doi.org/10.1038/s41612-020-00135-w

\section{INTRODUCTION}

In spite of continued improvements in the representation of physical processes and the unrelenting increase in spatial resolution, climate models still suffer from persistent biases in a number of key variables including precipitation and temperature. One particular bias common in a vast number of weather forecast and climate models is a too warm lower troposphere over the central United States ${ }^{1-7}$. The warm bias is severest over the US Great Plains and most significant during the boreal summer. Based on the results from 19 Coupled Model Intercomparison Project (CMIP) models, there is a robust dependence of the lower tropospheric warm bias along with a precipitation deficit leading the warm bias over this region ${ }^{1}$. Studies also show that the warm bias and precipitation deficit, hereafter referred to as the warmand-dry bias, is especially severe over the dry soil regime where the strength of land-atmosphere interactions is the strongest ${ }^{2}$. Given the nature of this bias and the unequivocal importance of the surface temperature and precipitation for both weather forecasting and climate applications, there is an urgent need to fully understand the bias origin.

Previous studies have proposed various theories and hypotheses explaining the warm-and-dry bias in atmospheric models over the central United States, including the Great Plains and the Midwest. Some studies posited the inability for coarse resolution models to simulate mesoscale convective systems (MCS) as a possible explanation for the precipitation deficit over the Great Plains ${ }^{1,3}$. MCSs account for over $50 \%$ of warm season precipitation in the central United States ${ }^{8}$. Indeed, underestimated convective clouds could result in excessive downward shortwave radiation and hence enhanced heating of the surface layer ${ }^{4}$. Furthermore, lack of prolonged and intense precipitation from MCSs could lead to drier soils and hence overestimated Bowen ratios, further enhancing the excess surface heating. A deficit in evapotranspiration in the CMIP5 models has been documented, spatially coincident over regions with a warm-and-dry bias ${ }^{5}$. Further complicating the land-surface feedback to precipitation, the role of soil moisture on local precipitation can be positive or negative, depending on the large-scale atmospheric environment and other factors ${ }^{9,10}$.

To untangle the inconclusive understanding of the mid-latitude warm bias, the CAUSES (Clouds Above the United States and Errors at the Surface) project was established, aiming to quantify how the physical processes associated with radiation, clouds, and land-atmosphere interactions contribute to the warm bias in the climate and weather forecast models, with a focus over the US Midwest and Great Plains ${ }^{2,6,11}$. Largely underestimated evaporative fraction (EF, defined as the ratio of latent heat flux to the sum of sensible plus latent heat fluxes) has been attributed as the dominant source of error in models with a large warm bias ${ }^{2}$. The net surface shortwave radiation is found to be overestimated in all models, primarily due to model underestimation of deep convective clouds ${ }^{11}$. Further, most models fail to capture the observed nocturnal precipitation peak over the Great Plains during the warm seasons, which is primarily related to propagating $\mathrm{MCSs}^{12}$. MCSs play a significant role in the climate system, because they produce prolific rainfall, which changes the energy and moisture distribution. Due to the large parameterization uncertainties associated with convection processes, climate models with coarse resolution often suffer from large biases in simulating the amount, intensity, location, and frequency of precipitation ${ }^{13,14}$, particularly when associated with MCSs. Failing to represent MCSs may also result in different land-surface response, as MCS precipitation may penetrate deeper into the soil, whereas non-MCS precipitation usually exists in shallower layers and evaporates more quickly, leading to drastically different land-atmosphere feedbacks ${ }^{15}$.

Irrigation, by artificially adding water over pasture or farm land when needed, perturbs the surface water and energy budgets,

${ }^{1}$ Pacific Northwest National Laboratory, Richland, Washington, USA. ${ }^{2}$ School of Atmospheric Sciences, Nanjing University, Nanjing, China. ${ }^{3}$ Lawrence Livermore National Laboratory, Livermore, California, USA. ${ }^{凶}$ email: yun.qian@pnnl.gov 
and could possibly modulate local to regional atmospheric processes and land-atmosphere interactions ${ }^{16}$. Irrigation is critical in meeting water demand and ensuring high crop yields over regions lacking sufficient rainfall during the growing season. In 2012 , irrigated farms accounted for $\sim 50 \%$ of the total value of US crop sales on $28 \%$ of the US harvested cropland ${ }^{17}$. In 2015 , total irrigation withdrawals accounted for $42 \%$ of total freshwater withdrawals in the United States and over $80 \%$ of water consumptive use was for irrigation purposes ${ }^{18}$.

Irrigation affects the local surface energy and water budgets ${ }^{19}$ and planetary boundary layer (PBL) evolution. Many studies have attempted to quantify the impact of irrigation on weather, climate, and hydrology at the local and continental scales ${ }^{16,20-23}$. The processes by which irrigation affects convective cloud formation and MCSs are complicated and uncertain due to the large uncertainties associated with convective parameterization and complex multi-scale interactions between soil moisture, landsurface heterogeneity, and the atmosphere.

Previous observational or modeling studies ${ }^{16,22,24-27}$ focusing on irrigation impact over the Central Plains have either qualitatively or quantitatively shown that irrigation increases precipitation over or downwind of the irrigated regions and, therefore, reduces the dry biases over the Great Plains. However, to the best of our knowledge, no previous study has linked irrigation with summer MCSs over the Central United States. Simulations of MCSs are a longstanding challenge for climate simulations and models with parameterized convection. Traditional global or regional climate models (GCMs and RCMs hereafter) with parameterized convection cannot simulate MCSs, because convection parameterizations used in coarse models are not designed to handle organized convection and the associated multi-scale interactions. Failure of GCMs or RCMs to simulate MCSs is reflected in an erroneous diurnal cycle of precipitation and a large warm bias in the near-surface temperature ${ }^{1}$. Although convection-permitting climate models can simulate realistic MCSs, they still exhibit a large summertime dry bias over the Midwest ${ }^{28}$. For example, a long-term RCM simulation over Contiguous United States (CONUS) at a convective-resolving scale found that the simulated number of MCSs in the central United States during summer are underestimated by more than $70 \%$ and the MCS precipitation amount is only about $50 \%$ of the observed quantity.

In this study, we conduct convection-permitting simulations for two growing seasons over the CONUS using the Weather Research and Forecasting (WRF) model coupled with an operational-like irrigation scheme within the Noah land-surface model. We aim to test the hypothesis that by considering irrigation at the convection-permitting scale, enabling the more realistic characterization of both the land surface and the convection processes would yield better representation of land-atmosphere interactions over the Great Plains and potentially alleviate the warm-anddry bias over this region. To evaluate that, we have investigated the impact of irrigation on MCSs, total precipitation, and their diurnal cycles and surface temperature fields. The goal is to quantify how much model biases in precipitation and surface air temperature could be reduced by considering the irrigation effect.

\section{RESULTS}

We perform WRF simulations with $4 \mathrm{~km}$ horizontal grid spacing, which permits turning off the convection parameterization. Model configuration settings, such as the physics parameterizations and forcing data, are described in the "Methods" section. Our experimental design, highlighted by use of convectionpermitting resolution and a large domain covering the entire CONUS without nudging applied to the simulations, facilitates the interaction between the land surface and atmospheric processes within a dynamically evolving system. The operational-like dynamic irrigation scheme is described in the "Methods" section.
The irrigation area and irrigated water amount is shown in Supplementary Fig. 1 of the Supplementary Material.

\section{Irrigation impact on MCS}

Comparing to observations, the dry bias shown in the control simulation is reduced by irrigation, mainly through more MCS precipitation. The seasons from 2011 and 2012 are averaged together in our analyses unless otherwise noted. The MCSs in observations and model simulations are tracked using the Flexible object TRacKeR (FLEXTRKR) algorithm based on observed and simulated three-dimensional (3D) radar reflectivity and top-ofatmosphere infrared brightness temperature ${ }^{29,30}$. Details of the observations and tracking methodology are provided in the "Methods" section. The observations show significant MCS precipitation over the northern Great Plains and the Midwest during summer, with maximum values larger than $2 \mathrm{~mm}$ day ${ }^{-1}$. The MCS precipitation is underestimated in the control (CTL) simulation without irrigation, especially over the central Great Plains (Fig. 1a-c). This underestimated summer MCS precipitation is consistent with previous convection-permitting climate simulations ${ }^{28,29}$. Adding irrigation clearly reduces the dry bias in MCS precipitation (Fig. 1c-e). Large regions within the central Great Plains show more than a doubling of MCS precipitation compared to the CTL simulations, particularly over areas where CTL significantly underestimates observed MCS rainfall (western and central portion of the magenta box). The probability density function shows an average increase of $\sim 65 \%$ (green solid line in the inset plot of Fig. 1f), with a long tail of up to $800 \%$ relative increase in some areas. Summer MCSs over the Great Plains commonly occur under weak synoptic forcing, with weak lowlevel convergence acting on the warm humid air associated with the low-level jet (LLJ) ${ }^{12}$. Initiation of summer MCSs are likely more sensitive to local or regional disturbances, particularly within the boundary layer.

Observations show a very strong diurnal cycle of summer MCS precipitation over the Central United States (identified by the magenta box in Fig. 1) spanning $105^{\circ} \mathrm{W}$ to $85^{\circ} \mathrm{W}$ (Fig. 2a, d). MCS precipitation peaks around midnight or early morning over most of areas in the central United States. Most MCSs initiate during local late-afternoon hours during summer. Observations also show a clear eastward propagation of the MCS precipitation over the Great Plains. Many MCSs initiate just east of the foothills of the Rocky Mountains $\left(105^{\circ} \mathrm{W}\right)$ where the terrain gradient is sharpest, whereas others initiate over the Great Plains (Fig. 2a, d). Compared with the observations, the simulated MCS precipitation in the control experiment is much smaller in both area and magnitude (Fig. 2b, e). Without irrigation, the model fails to capture the maximum MCS precipitation over much of the central Great Plains. Even over the eastern portion of the Great Plains (east of $95^{\circ} \mathrm{W}$ ) the model underestimates the magnitude of the MCS precipitation diurnal cycle, with delayed initiation time, which could subsequently affect the soil moisture and land-atmosphere-cloud interactions.

With irrigation turned on, the total number of simulated MCS events over the Central U.S. increases from 38 to $63(66 \%$ increase), closer to the observed 95 MCS events during the two summer seasons. As a result of more MCS events, MCS precipitation frequency is substantially increased, resulting in a reduction of the overall dry bias versus observations (see Supplementary Figs. 2 and 3). Irrigation simulations (IRI) significantly increase MCS precipitation originating from the Rocky Mountain foothills by more than three times between late afternoon to early morning hours compared to the CTL (Fig. 2c, f). Other characteristics associated with MCSs, including MCS lifetime, precipitation feature size, mean rain rate, and convective intensity, are also examined but show no clear difference between the irrigation and control simulations (Fig. 3). Evidently, irrigation 

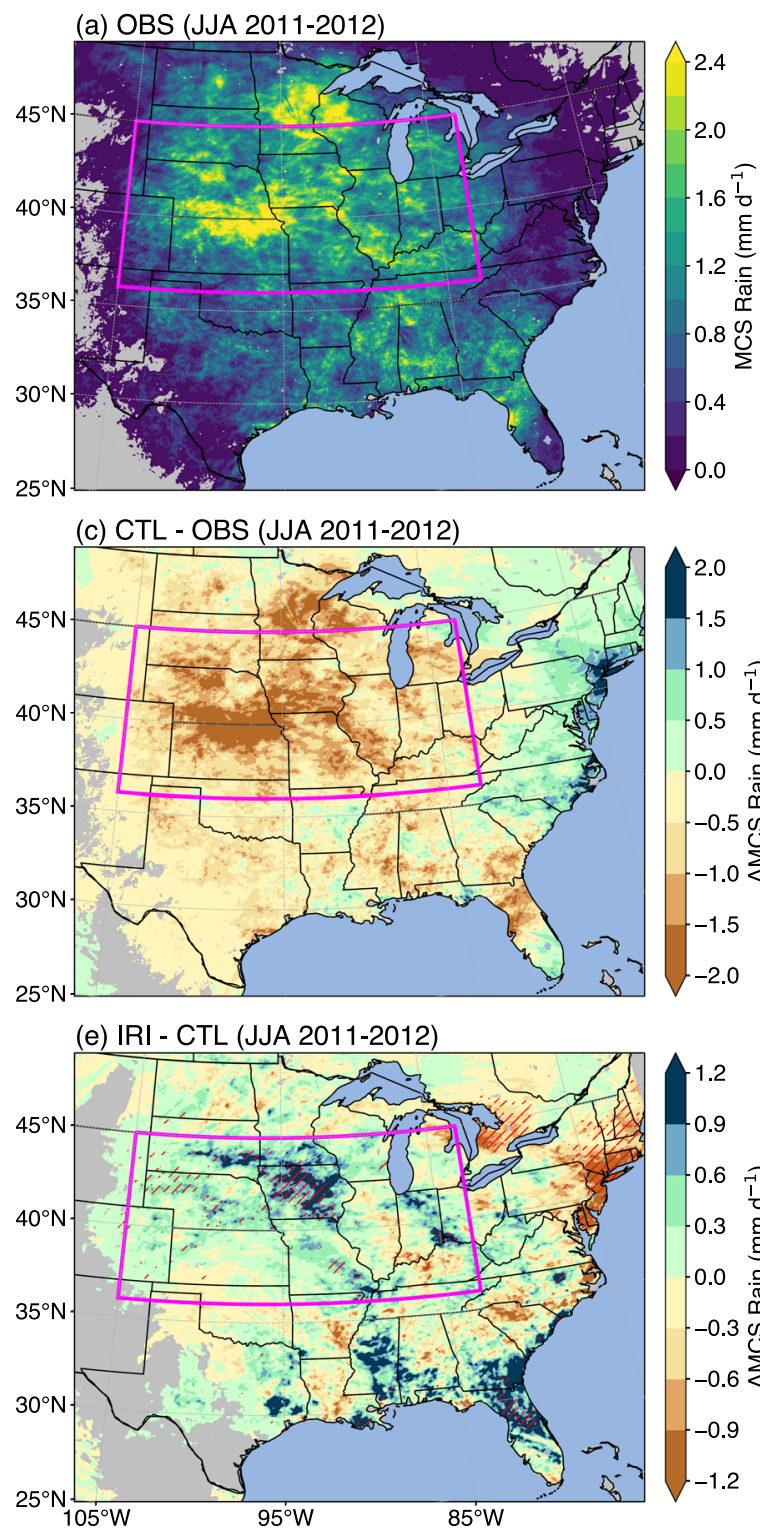

(b) CTL (JJA 2011-2012)

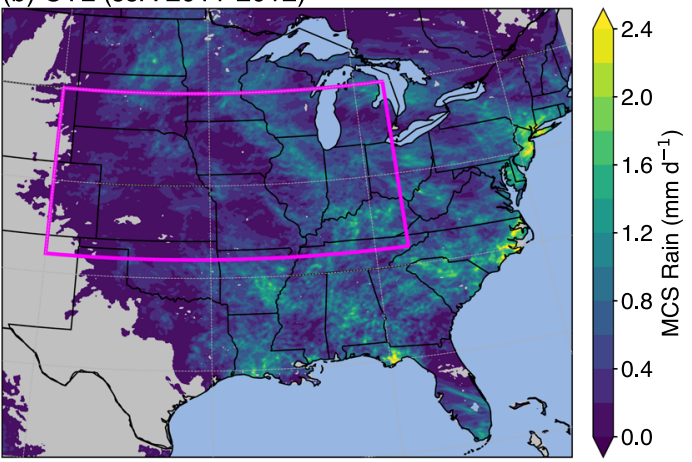

(d) IRI - OBS (JJA 2011-2012)
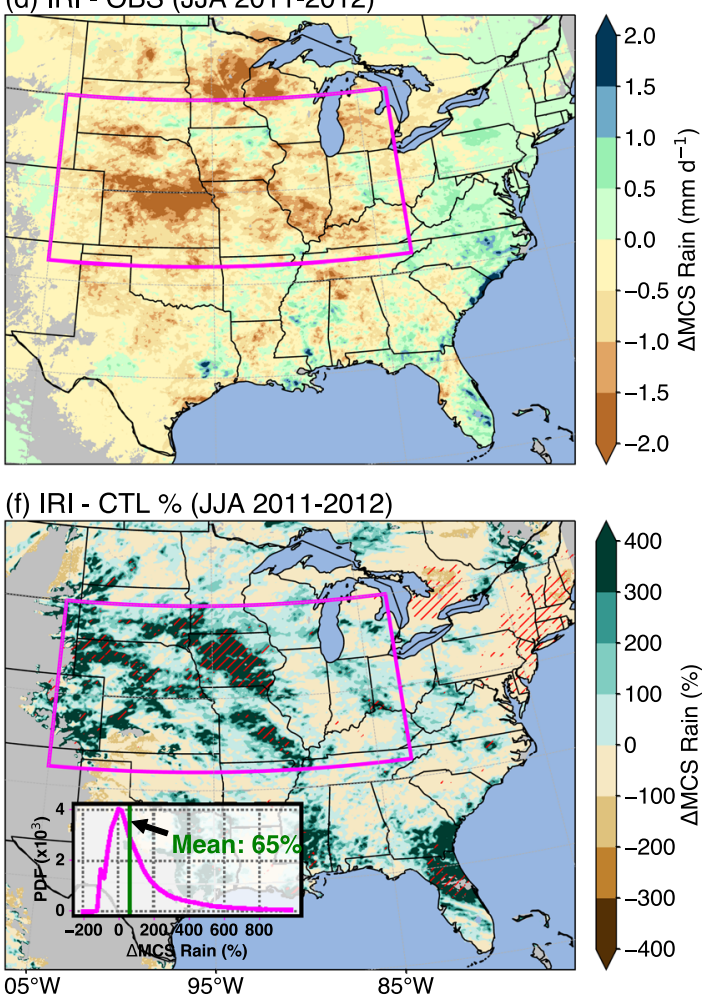

Fig. 1 Spatial distribution of MCS precipitation in June-July-August (JJA) averaging over 2011 and 2012. MCS precipitation from (a) NSSL Q2 multi-sensor precipitation observations, (b) the control (CTL) simulation, (c) difference between control simulated and observed MCS precipitation, (d) same as c, except for irrigation (IRI) simulation, (e) irrigation-induced changes, and (f) same as e, except shown in percentages. The magenta box indicates the region used for the Hovmöller diagram in Fig. 2 . The red hatches in e, $\mathbf{f}$ denote statistically significant differences at the $90 \%$ interval. The inset in $\mathbf{f}$ shows the probability density function of the percentage change over the magenta box and the green solid line in the inset shows the average change $(\sim 65 \%)$.

increases the MCS precipitation amount over and downwind of the irrigated areas via more frequent MCS events rather than changing the internal dynamics and structure of MCSs. Compared with the CTL, the IRI shows a much stronger eastward propagation of the MCS precipitation, particularly for MCSs initiated near the Rocky Mountain foothills, which is much more consistent with the observations and suggests a significant improvement of the MCS precipitation diurnal cycle (Fig. 2). As nocturnal peak precipitation is primarily contributed by MCSs in the Great Plains during summer ${ }^{31-35}$, our results suggest irrigation, through improving the MCS precipitation, plays a very important role in capturing the observed nocturnal peak precipitation in this region.

Figure 4 shows the comparison of observed and simulated total precipitation averaged over the central Great Plains (34-47 $\left.\mathrm{N}, 105-89^{\circ} \mathrm{W}\right)$. To represent the observational uncertainty of precipitation, we include two precipitation datasets (see "Methods" for details of the reference precipitation datasets). Averaged total precipitation peaks around 1900-2000 Local time (LT) for both summer seasons and declines to a minimum at local noon. Total precipitation is contributed by both isolated convection and MCSs, which have different peak hours around late afternoon (i.e., 1800 LT) and midnight, respectively. MCS precipitation usually dissipates quickly after sunrise due to weakening of the nocturnal LLJ ${ }^{36}$.

GCMs and RCMs with coarse resolution struggle to capture the diurnal timing of peak precipitation related to propagating convection in the Great Plains ${ }^{14,37,38}$. The convection-permitting simulations here produce more reasonable diurnal cycle of precipitation compared to convection-parameterized simulations, although the magnitude of peak rainfall from late afternoon to evening is still underestimated. Irrigation moves the peak of the nocturnal rain earlier by $2 \mathrm{~h}$, while maintaining the correct time of the mid-day minimum, which is more consistent with the observations. The control simulation without irrigation only 

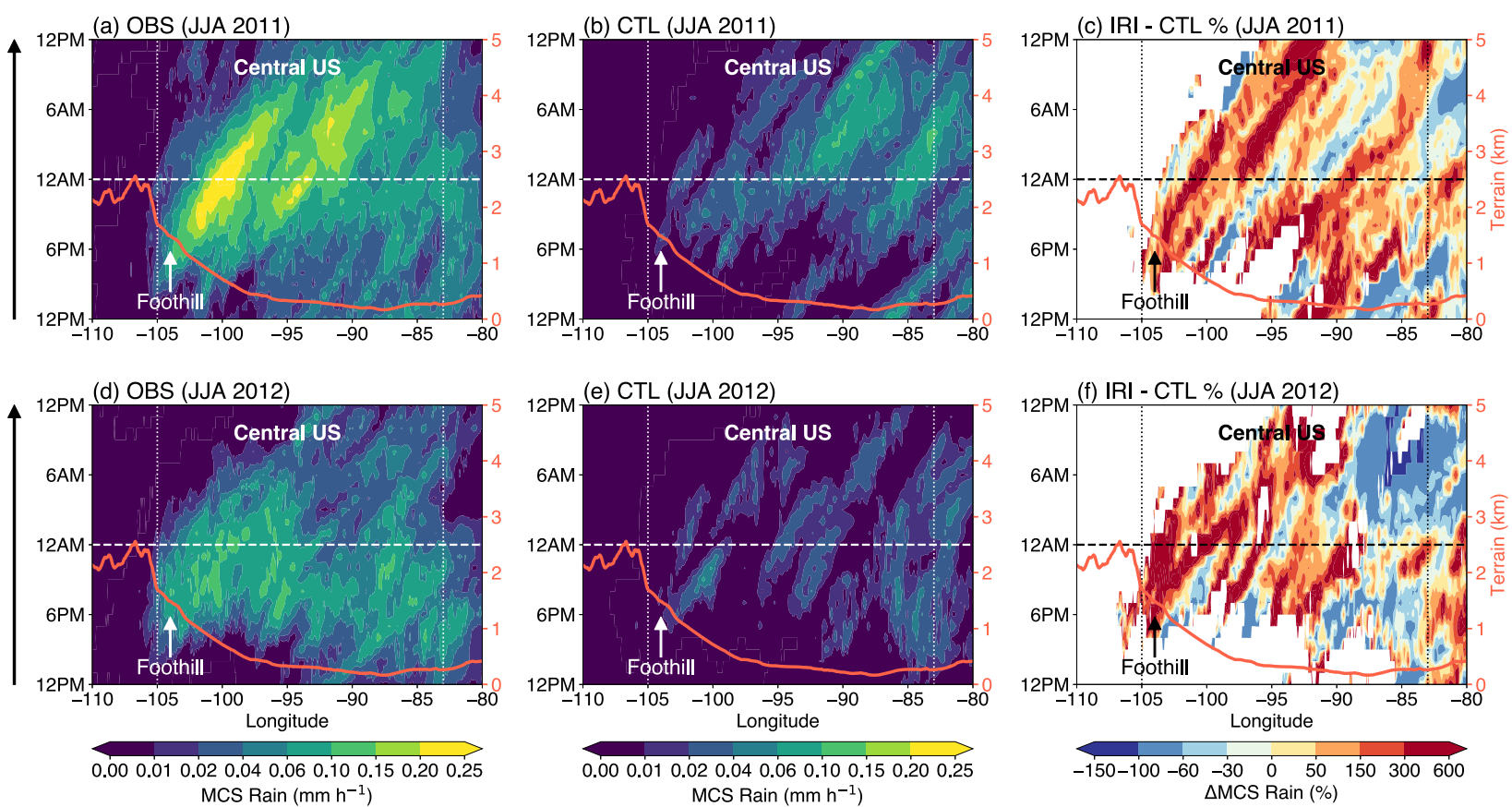

Fig. 2 Diurnal cycle of MCS precipitation as a function of longitude. Hovmöller diagram averaged in June-July-August of 2011 (top) and 2012 (bottom). a Observed diurnal variation of MCS precipitation from Stage-IV observations in 2011. b Same as a but from the control simulation. c Irrigation-induced change in MCS precipitation shown in percentages. $\mathbf{d}-\mathbf{f}$ are similar as a-c but for 2012. Local time is set to US Central Time Zone (UTC-06:00). Latitudinally averaged terrain height in the Central United States is shown as the orange line. Labels indicate locations of the Rocky Mountain foothills and Central United States.

(a) MCS Lifetime

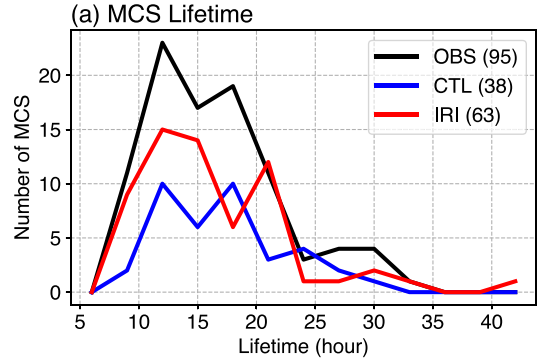

(c) MCS PF Mean Rain Rate

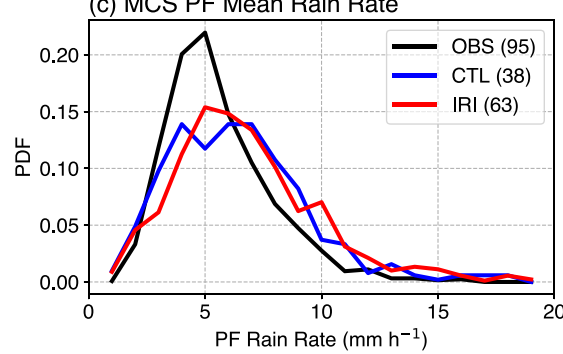

(b) MCS PF Diameter

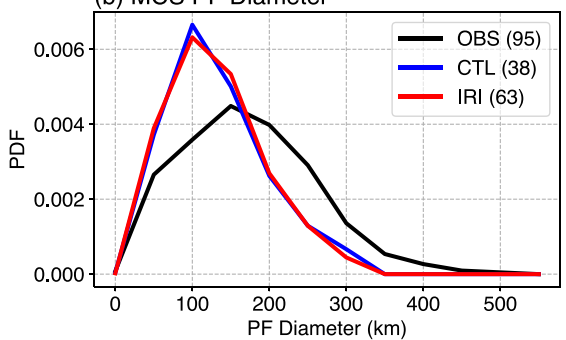

(d) MCS Max 40dBZ ETH

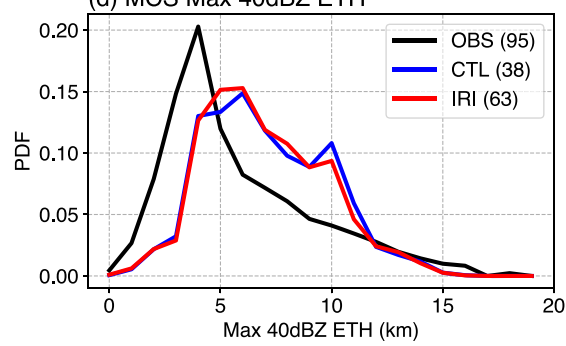

Fig. 3 Comparison of MCS characteristics between observations and control and irrigation simulations. MCS characteristics are shown for (a) MCS lifetime, (b) MCS precipitation feature (PF) diameter, (c) MCS PF averaged rain rate, and (d) MCS max 40 dBZ convective echo-top heights (a proxy for convective intensity). Observation (OBS) is in black, control (CTL) is in blue, and irrigation (IRI) simulation in red. Numbers in the parenthesis indicate the number of MCSs in each dataset. MCSs during JJA for both 2011 and 2012 over the central United States and Midwest region (magenta box in Fig. 1) are selected for comparison.

captures one-third of the observed total rainfall, and the dry bias is largest for nocturnal peak precipitation, which is mainly controlled by MCSs.

With irrigation turned on, the total precipitation increases by 20-30\% during the strongly precipitating nighttime and by $50-80 \%$ during the less precipitating daytime, and the overall dry bias in the central US region is reduced by $30-50 \%$. The magnitude of peak precipitation is still significantly underestimated, which suggests irrigation effects can only partially account for the precipitation deficit over the central United States. Other biases in the model, such as the LLJ and associated moisture transport, coupled with land-atmosphere interactions, and various feedback processes, uncertainties associated with $4 \mathrm{~km}$ grid spacing properly representing shallow convection and convective 

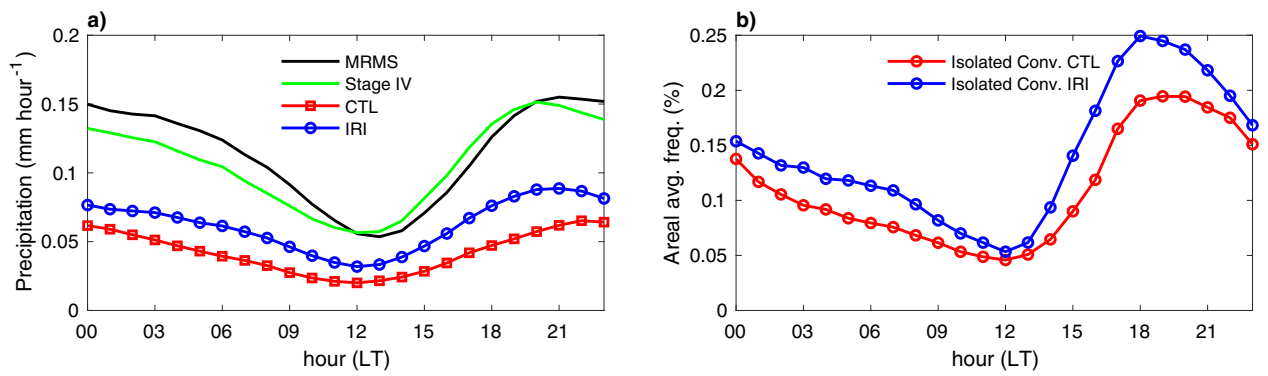

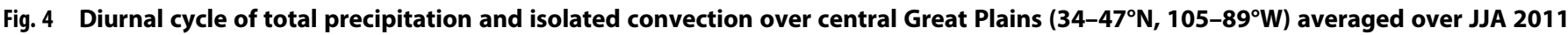
and 2012. a Areal-averaged total precipitation from two observations (MRMS and Stage-IV) and model with irrigation on (blue) and off (red), respectively. Units: $\mathrm{mm} \mathrm{h}^{-1}$. b Areal-averaged isolated convection frequency from IRI (blue) and CTL simulations. Local time (LT) is set to US Central Time Zone (UTC - 06:00).

triggering (4 km does not fully resolve isolated convection), and $\mathrm{PBL}$ processes may also contribute to the bias.

To better understand the physical processes impacted by irrigation and how the changes affect convection and clouds, we examine the changes in the thermodynamic environments between the two simulations. First, irrigation increases moist static energy within the low and middle boundary layer (not shown). Simulations show that irrigation causes decreases in both PBL depth and lifting condensation level (LCL), with a spatial pattern similar to that of changes in surface evapotranspiration and latent heat flux (not shown). However, the irrigation-induced decrease in the $L C L$ is greater than that for the PBL depth (Fig. 5a), leading to more frequent occurrences of lifted air parcels crossing above the $\mathrm{LCL}$, suggesting that the probability of shallow convective cloud formation would increase due to irrigation. Shallow cumulus plays a key role in preconditioning the atmosphere for deep convection through moistening the lower free troposphere via detrainment of water vapor from the boundary layer ${ }^{39}$.

Convective Available Potential Energy (CAPE), a measure of the amount of energy available for convection, is an indicator of atmospheric instability in predicting intensity of convection by quantifying the uplift potential of an air parcel. In general, increased moisture at low levels increases CAPE, increasing the likelihood of convective precipitation ${ }^{40-42}$. In contrast, a cooler land surface may enhance convective inhibition (CIN), suppressing the initiation of deep convection ${ }^{25,40,43,44}$. By decreasing surface temperature and increasing moisture, irrigation contributes to competing effects on the development of convection at local scales over the irrigated areas (Fig. 5). Downwind of the irrigated region over the Midwest, there is clear evidence of increased $\mathrm{LCL}$ crossing throughout the afternoon along with decreased $\mathrm{CIN}$, which favors convective initiation and explains the increased lateafternoon isolated convection frequency over the northern Great Plains (Figs. $4 \mathrm{~b}$ and 5). More frequent late-afternoon convective initiation, along with more favorable thermodynamic conditions (increased CAPE and a moister boundary layer) results in more upscale growth of isolated convection to form MCSs during early evening hours (Fig. 2). The thermodynamic environmental changes (Fig. 5) are spatially coherent with the increased daily average precipitation (see Supplementary Fig. 3). CAPE, CIN, and $\mathrm{LCL}$ crossing during the morning and the middle of the day are also examined, and we find spatially consistent changes similar to those in late-afternoon hours (Supplementary Figs. 4 and 5).

\section{Irrigation impact on temperature}

Most contemporary global climate and weather forecasting models exhibit a large systematic warm bias during the summertime over the Great Plains ${ }^{1-3}$. Figure $6 a$ shows the $2 \mathrm{~m}$ height surface air temperature bias over CONUS during summer averaged from CMIP5 GCMs. Our CTL simulation shows a very similar spatial pattern of warming bias when compared with PRISM (Fig. 6b). Previous studies ${ }^{4,11}$ suggest the overestimated net surface shortwave radiation is the main cause of the warm bias and errors in simulating clouds (underestimation) are the primary contributor to the overestimated net surface radiation. This warm bias also coincides with underestimated evapotranspiration and $\mathrm{EF}$, soil moisture, and precipitation, which are mainly caused by the models' inability to simulate MCSs, besides the models' cloudrelated radiation errors.

Alternatively, irrigation adds water to croplands and pastures over large portions of the United States, increasing evapotranspiration, EF, and low-level moisture, resulting in an increase in shallow convective cloud formation and MCS frequency. Surface cooling results from the repartitioning of net radiation into latent heat flux at the expense of sensible heat flux. Adding irrigation has drastically reduced the warming bias by $\sim 1-2 \mathrm{~K}$ over the majority of the United States (Fig. 6c). When compared to in situ observations collected at the Atmospheric Radiation Measurement (ARM) Southern Great Plains atmospheric observatory in Oklahoma, the warm bias is reduced by $\sim 1.2 \mathrm{~K}$ when irrigation is considered $^{19}$. Given the similar spatial pattern between the common warm bias in climate models and the cooling effect of irrigation, we illustrate that the neglect of irrigation partly accounts for the warm bias in climate models over the central United States. Our results show that irrigation-induced changes in surface air temperature, surface fluxes, clouds, and precipitation are spatially consistent over the majority of the central United States, suggesting a tight physical link between the surface energy and water cycle and a strong land-atmosphere-cloud coupling over the central United States during summer. In addition, irrigation occurs over a large enough area that it sufficiently perturbs the associated processes to alter the climate.

\section{DISCUSSION}

A vast number of weather forecast and climate models exhibit a warm-and-dry bias over the central United States during the boreal summer. The lack of precipitation and soil moisture in the models, accompanied by underestimated evapotranspiration and overestimated surface net radiation, can enhance the surface air temperature bias through land-atmosphere-cloud interactions ${ }^{1,2,16}$. Our modeling results at convection-permitting resolution show that irrigation, by adding water to the surface, results in a more conducive thermodynamic environment for convective initiation highlighted by increased CAPE over the irrigated region, higher probability of $\mathrm{LCL}$ crossing, and reduced CIN over the downwind regions. Such changes in the thermodynamic environment, especially over the downwind regions, facilitate the formation of shallow convective clouds and late-afternoon 

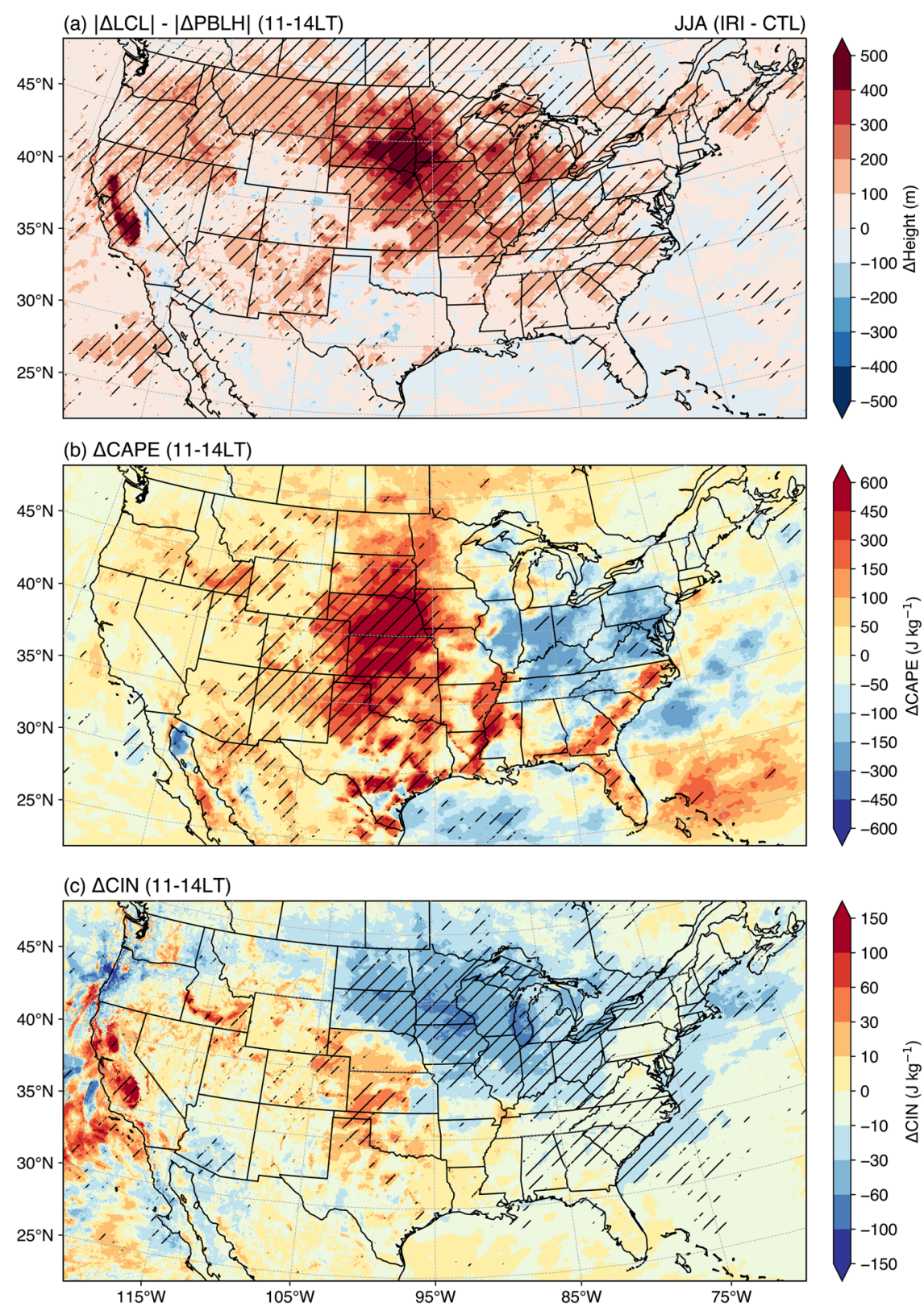

Fig. 5 Irrigation-induced changes in thermodynamic variables in the late afternoon (1500-1800 LT). a Difference between irrigationinduced change in LCL and changes in PBL height. Positive values indicate a higher probability of LCL crossing and more low-level clouds, b irrigation-induced change in CAPE, c irrigation-induced change in CIN. Regions with statistically significant changes at the $10 \%$ level are indicated with striping.

isolated convection ${ }^{16}$. The increased isolated convection, through aggregation and upscale growth, explains the increase in the number of MCS events and MCS precipitation frequency, ultimately increasing total precipitation.

Approximately $30-70 \%$ of the total precipitation is contributed by MCSs in the warm season over the Central United States ${ }^{36,45}$. Observations show that both the intensity and frequency of MCSs have significantly increased in the past several decades over the this region ${ }^{36}$. Considering (1) irrigation water use has increased significantly in the past several decades and (2) our results in this study indicate irrigation increases the MCS frequency and related precipitation, we posit that irrigation may have contributed to the observed increase in MCS activity and associated extreme weather events, since MCSs are the largest type of convective storm and many MCSs also produce extreme weather such as flooding, hail, strong winds, and sometimes even tornados over the central United States ${ }^{46}$.

Surface cooling results from the repartitioning of net radiation into latent heat flux at the expense of sensible heat flux to the first order. Moreover, by more realistically simulating MCSs, the warmand-dry bias induced through the positive feedback between soil moisture and air temperature is improved. Given the coherent spatial structure and opposite sign in surface temperature between the common model bias and irrigation effect, we argue that including irrigation can reduce model bias at a process level in simulations of surface air temperature and precipitation including its diurnal cycle.

In this study, irrigation is triggered in the model when root zone soil moisture availability (MA) is below a specific threshold ${ }^{16}$. We assume water availability for irrigation from surface or underground is unlimited. In reality, irrigation water use could be 
(a) CMIP5/AMIP JJA 2m Temperature Bias
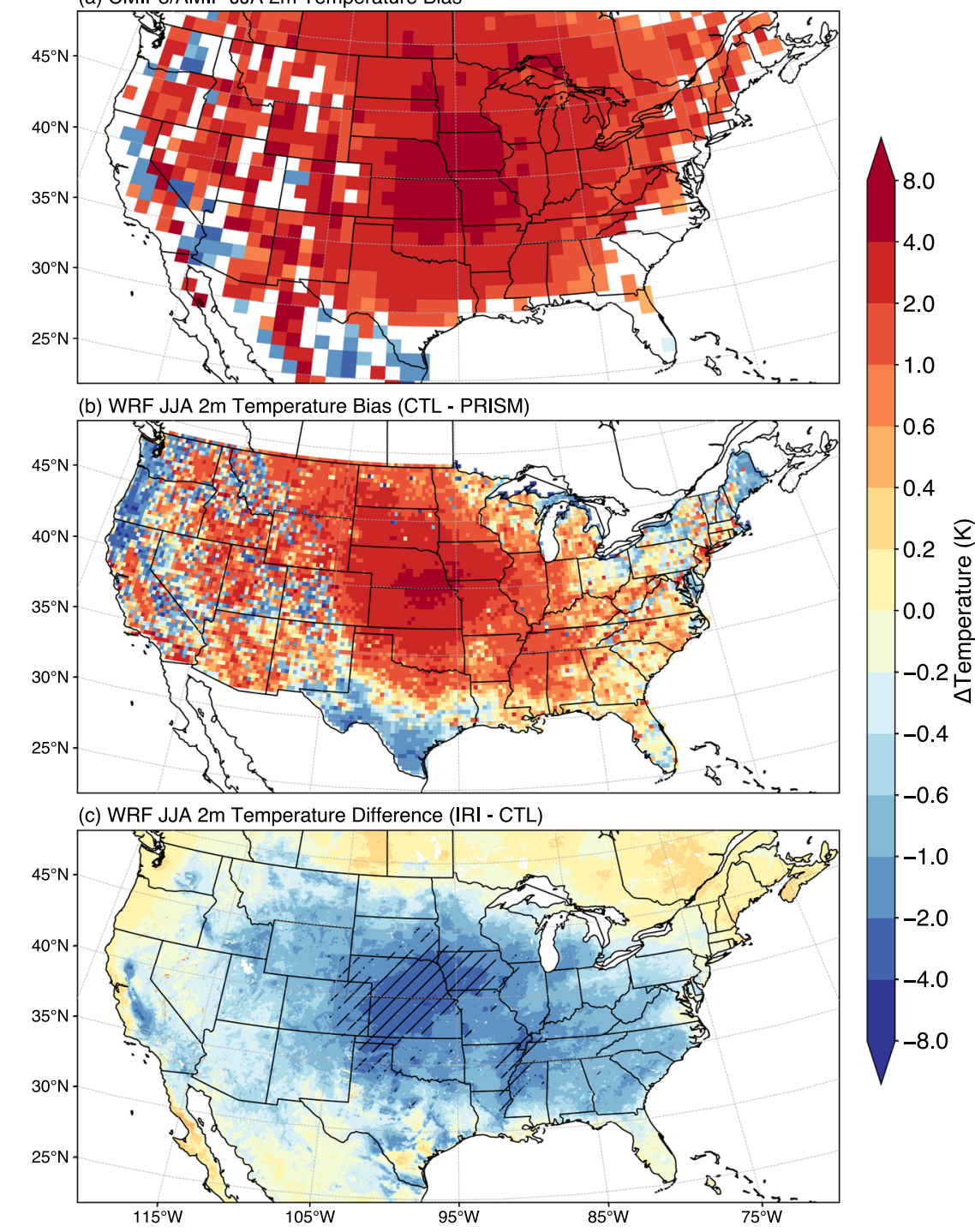

0

Fig. 6 Spatial pattern of temperature biases in global and regional climate simulations and irrigation-induced cooling. a Systematic $2 \mathrm{~m}$ air temperature bias in global climate models (see details of GCMs and reference dataset in the "Methods"), b $2 \mathrm{~m}$ air temperature bias in the control simulation against PRISM observations, and c irrigation-induced cooling simulated in this study. Only areas with a statistically significant bias at $95 \%$ confidence intervals are plotted in a, while areas exceeding the $95 \%$ confidence interval are shown in hatches in c.

modulated by various factors, such as irrigation methods (e.g., sprinkler, drip, or flood irrigation), water availability, cost, or other logistical issues, leading to uncertainty in the amount of irrigation water to apply in the model. However, this will not qualitatively change the overall conclusion of this study.

An important methodological decision for this study is the use of convection-permitting grid spacing. This enables more realistic simulation of convective processes by not needing to use a deep convection parameterization. These parameterizations have known biases and issues properly responding to CAPE and CIN perturbations to provide accurate representations of large-scale convection, e.g., convection parameterizations do not accurately reproduce the precipitation diurnal cycle $^{47}$ and thus could impact the timing of the irrigation. The associated trade-off of increasing the accuracy of the precipitation processes is a large increase in computation cost. We thus only performed simulations for two warm seasons in 2011 and 2012. Given that the differences from the irrigation effect are less than $20 \%$ between these two seasons, we believe the overall conclusions will not change if the simulation were to be

Table 1. Parameterizations used in the WRF model setup.

Microphysics

Radiation

Planetary boundary layer

Land surface model

extended to more years. Future studies should focus on precipitation change over the east coast, given irrigationinduced precipitation change is quite large there, as well as the changes in circulation and low-level moisture transport.

\section{METHODS}

Models

The Advanced Research WRF version 3.8.1 was used in this study with physical parameterization summarized in the Table $1^{48}$. The model domain covers the contiguous United States plus the western and eastern costal 
oceans, with horizontal grid spacing of $4 \mathrm{~km}$ and 65 vertical levels from the surface to $50 \mathrm{hPa}$. The initial atmospheric and soil conditions, as well as three-hourly lateral boundary conditions were obtained from NCEP FNL (Final) Operational Global analysis data. The model outputs were archived hourly to enable tracking of MCSs. Two sets of simulations, with irrigation on or off, respectively, were conducted from March 15 to 31 October for both 2011 and 2012, with each simulation extending continuously for the entire respective period.

\section{Irrigation scheme}

An operational-like irrigation scheme was coupled to the land surface component (i.e., Noah) of the WRF model to mimic sprinkler-type irrigation over the contiguous United States ${ }^{16}$. The reason for choosing sprinkler over flooding and dripping is that by far it is still the most common irrigation method used in the United States. The land use and land cover information in the model is based on the Moderate Resolution Imaging Spectroradiometer (MODIS) 21-category data following the International Geosphere-Biosphere Programme classification. A global map of potential irrigated areas at a resolution of 5 arc min, provided by the Food and Agriculture Organization ${ }^{49}$, is incorporated and regridded to the model grid ( $4 \mathrm{~km}$ grid spacing). For a model grid cell to be possibly irrigated, the land cover type needs to be cropland or pastures with irrigation fraction greater than zero.

Irrigation is triggered only during the growing season (April-October) when soil MA is below a certain threshold. Growing season is defined such that green vegetation fraction (GVF) needs to be greater than a threshold $\left(\mathrm{GVF}_{\text {thresh }}\right)$ defined following the equation:

$\mathrm{GVF}_{\text {thresh }}=\mathrm{GVF}_{\text {min }}+0.4 \times\left(\mathrm{GVF}_{\max }-\mathrm{GVF}_{\text {min }}\right)$

where $\mathrm{GVF}_{\min }$ and $\mathrm{GVF}_{\max }$ are the minimum and maximum monthly GVF based on MODIS climatological value. During growing seasons, irrigation will be triggered when root zone soil moisture availability (MA) is $<0.5$. The moisture availability is defined as follows:

$\mathrm{MA}=\frac{\mathrm{SM}-\mathrm{SM}_{\mathrm{WP}}}{\mathrm{SM}_{\mathrm{FC}}-\mathrm{SM}_{\mathrm{WP}}}$

where $\mathrm{SM}$ is the soil moisture content, $\mathrm{SM}_{\mathrm{FC}}$ and $\mathrm{SM}_{\mathrm{WP}}$ are the soil moisture field capacity and wilting point, respectively.

The amount of water irrigated is calculated as the difference between soil moisture holding capacity and current soil moisture content over the soil column at the time when irrigation is triggered. Then, irrigated water is distributed evenly and behaves like precipitation to mimic sprinkler irrigation through a $4 \mathrm{~h}$ time window starting from 0600 to 1000 LT.

\section{Observations}

The observations used to identify MCSs in this study are similar to those used by Feng et al. ${ }^{29}$. The 3D mosaic Next-Generation Radar radar reflectivity dataset over CONUS is obtained from the National Severe Storm Laboratory Multi-Radar Multi-Sensor (MRMS) system ${ }^{50}$. The MRMS 3D radar reflectivity has spatiotemporal resolution of 1 and $5 \mathrm{~min}$, respectively. Quantitative precipitation estimates using high-resolution $(1 \mathrm{~km})$ mosaic radar data with rain gauge network bias correction, known as the Q2 precipitation product (obtained from https://www.nssl.noaa.gov/projects/ $\mathrm{mrms} /$ ), are also available every hour. The merged geostationary satellite brightness temperature $\left(T_{\mathrm{b}}\right)$ data ${ }^{51}$ (https://doi.org/10.5067/ P4HZB9N27EKU) are obtained from the NASA Goddard Earth Sciences Data and Information Services Center. The satellite dataset has spatiotemporal resolution of $4 \mathrm{~km}$ and $30 \mathrm{~min}$, respectively. The MRMS 3D radar and Q2 datasets are regridded to match the satellite $4 \mathrm{~km}$ grid every hour, which is used to track MCSs. A second high-resolution precipitation product from the Stage-IV multi-sensor precipitation dataset (https://doi. org/10.5065/D6PG1QDD) is also used in this study. The Stage-IV precipitation is produced by the 12 River Forecast Centers in the continental United States, available at $4 \mathrm{~km}$ every hour ${ }^{52}$.

\section{MCS tracking}

Long-lived and intense MCSs are tracked using the FLEXTRKR algorithm described in detail by Feng et al. ${ }^{29}$. FLEXTRKR uses $T_{\mathrm{b}}$ to identify and track large cold-cloud systems associated with deep convection, and further identifies MCS based on the duration, size and intensity of the radar echo signatures. MCS is defined as a cold-cloud system that exceeds a horizontal area of $60,000 \mathrm{~km}^{2}$, with a precipitation feature extending longer than $100 \mathrm{~km}$ in any direction, and an embedded convective radar echo stronger than $50 \mathrm{dBZ}$. All of these criteria must be met continuously for longer than $6 \mathrm{~h}$. These convective systems are designated as long-lived and intense MCSs, and they account for $46 \%$ of observed warm-season total rainfall in $2011^{29}$. The same criteria were applied to the model simulated radar reflectivity and outgoing longwave radiation, which was converted to equivalent $T_{\mathrm{b}}$, for consistent MCS identification and tracking.

\section{GCMs and reference dataset}

The GCM simulations are from the fifth phase of the CMIP $5^{53}$ Atmospheric Model Intercomparison Project experiment. Thirty model simulations are obtained from the Earth System Grid Federation (https://esgf-node.llnl. gov/projects/esgf-IInl/). Only one ensemble member (r1i1p1) from each model is used. The observed monthly $2 \mathrm{~m}$ air temperature is station data from the University of Delaware Air Temperature version $5^{54}$. All data are interpolated onto $1^{\circ} \times 1^{\circ}$ horizontal degree.

\section{DATA AVAILABILITY}

NCEP FNL datasets are available at https://rda.ucar.edu/datasets/ds083.2/. The irrigation fraction map is available at http://www.fao.org/aquastat/en/geospatialinformation/global-maps-irrigated-areas. Observed MRMS precipitation estimation is available at https://www.nssl.noaa.gov/projects/mrms/. The merged geostationary satellite brightness temperature $\left(T_{\mathrm{b}}\right)$ data55 is available at https://doi.org/10.5067/ P4HZB9N27EKU. Stage-IV precipitation is available at https://doi.org/10.5065/ D6PG1QDD. All the GCM results are available at the Earth System Grid Federation (ESGF) from https://esgf-node.Ilnl.gov/projects/esgf-Ilnl/. The datasets generated and/ or analyzed during the current study are available in the repository at https://portal. nersc.gov/project/m1660/yang560/IRI_MCS/.

Received: 5 November 2019; Accepted: 18 July 2020; Published online: 17 August 2020

\section{REFERENCES}

1. Lin, Y. et al. Causes of model dry and warm bias over central U.S. and impact on climate projections. Nat. Commun. 8, 1-8 (2017).

2. Ma, H. Y. et al. CAUSES: on the role of surface energy budget errors to the warm surface air temperature error over the central United States. J. Geophys. Res. 123, 2888-2909 (2018).

3. Klein, S. A., Jiang, X., Boyle, J., Malyshev, S. \& Xie, S. Diagnosis of the summertime warm and dry bias over the U.S. Southern Great Plains in the GFDL climate model using a weather forecasting approach. Geophys. Res. Lett. 33, L18805 (2006).

4. Cheruy, F., Dufresne, J. L., Hourdin, F. \& Ducharne, A. Role of clouds and landatmosphere coupling in midlatitude continental summer warm biases and climate change amplification in CMIP5 simulations. Geophys. Res. Lett. 41, 6493-6500 (2014).

5. Mueller, B. \& Seneviratne, S. I. Systematic land climate and evapotranspiration biases in CMIP5 simulations. Geophys. Res. Lett. 41, 128-134 (2014).

6. Morcrette, C. J. et al. Introduction to CAUSES: description of weather and climate models and their near-surface temperature errors in 5 day hindcasts near the Southern Great Plains. J. Geophys. Res. 123, 2655-2683 (2018).

7. Zhang, C. et al. CAUSES: diagnosis of the summertime warm bias in CMIP5 climate models at the ARM southern Great Plains Site. J. Geophys. Res. 123, 2968-2992 (2018).

8. Haberlie, A. M. \& Ashley, W. S. A method for identifying midlatitude mesoscale convective systems in radar mosaics. Part I: segmentation and classification. J. Appl. Meteor. Climatol. 57, 1575-1598 (2018).

9. Taylor, C. M. et al. Frequency of Sahelian storm initiation enhanced over mesoscale soil-moisture patterns. Nat. Geosci. 4, 430-433 (2011)

10. Welty, J. \& Zeng, X. Does soil moisture affect warm season precipitation over the Southern Great Plains? Geophys. Res. Lett. 45, 7866-7873 (2018).

11. Van Weverberg, K. et al. CAUSES: attribution of surface radiation biases in NWP and climate models near the U.S. Southern Great Plains. J. Geophys. Res. 123, 3612-3644 (2018).

12. Feng, Z. et al. Spatiotemporal characteristics and large-scale environments of mesoscale convective Systems East of the Rocky Mountains. J. Clim. 32, 7303-7328 (2019)

13. Yang, B., Qian, Y., Lin, G., Leung, R. \& Zhang, Y. Some issues in uncertainty quantification and parameter tuning: a case study of convective parameterization 
scheme in the WRF regional climate model. Atmos. Chem. Phys. 12, 2409-2427 (2012).

14. Zhang, Y. \& Klein, S. A. Mechanisms affecting the transition from shallow to deep convection over land: inferences from observations of the diurnal cycle collected at the ARM Southern Great Plains site. J. Atmos. Sci. 67, 2943-2959 (2010).

15. Hu, H., Leung, L. R. \& Feng, Z. Observed warm-season characteristics of MCS and Non-MCS Rainfall and Their Recent Changes in the Central United States. Geophys. Res. Lett. 47, 46 (2020).

16. Qian, Y., Huang, M., Yang, B. \& Berg, L. K. A modeling study of irrigation effects on surface fluxes and land-air-cloud interactions in the Southern Great Plains. J. Hydrometeor 14, 700-721 (2013).

17. Dass, U. 2012 Census of Agriculture 1-695 (National Agricultural Statistics Service, 2014).

18. Dieter, C. et al. Estimated Use of Water in the United States in 2015 1-76 (USGS, 2018).

19. Yang, Z. et al. Irrigation impact on water and energy cycle during dry years over the United States using convection-permitting WRF and a dynamical recycling model. J. Geophys. Res. 124, 11220-11241 (2019).

20. Arcand, S. et al. Modeled changes to the Great Plains low-level jet under a realistic irrigation application. Atmos. Sci. Lett. 20, e888-10 (2019).

21. Pei, L. et al. Effects of irrigation on summer precipitation over the United States. J. Clim. 29, 3541-3558 (2016).

22. Harding, K. J. \& Snyder, P. K. Modeling the atmospheric response to irrigation in the Great Plains. Part I: general impacts on precipitation and the energy budget. J. Hydrometeor. 13, 1667-1686 (2012).

23. Sorooshian, S., Li, J., Hsu, K. L. \& Gao, X. How significant is the impact of irrigation on the local hydroclimate in California's Central Valley? Comparison of model results with ground and remote-sensing data. J. Geophys. Res. 116, D06102 (2011).

24. Alter, R. E., Fan, Y., Lintner, B. R. \& Weaver, C. P. Observational evidence that great plains irrigation has enhanced summer precipitation intensity and totals in the midwestern United States. J. Hydrometeor 16, 1717-1735 (2015).

25. DeAngelis, A. et al. Evidence of enhanced precipitation due to irrigation over the Great Plains of the United States. J. Geophys. Res. Atmos. 115, 959 (2010).

26. Huber, D., Mechem, D. \& Brunsell, N. The effects of Great Plains irrigation on the surface energy balance, regional circulation, and precipitation. Climate 2, 103-128 (2014)

27. Mahmood, R. et al. Impacts of irrigation on 20th century temperature in the northern Great Plains. Glob. Planet. Change 54, 1-18 (2006).

28. Prein, A. F. Simulating North American mesoscale convective systems with a convection-permitting climate model. Clim. Dyn. 0, 0-0 (2017).

29. Feng, Z. et al. Structure and evolution of mesoscale convective systems: sensitivity to cloud microphysics in convection-permitting simulations over the United States. J. Adv. Modeling Earth Syst. 10, 1470-1494 (2018).

30. Feng, Z. et al. Spatiotemporal characteristics and large-scale environments of mesoscale convective Systems East of the Rocky Mountains. J. Clim. 32, 7303-7328 (2019).

31. Wallace, J. M. Diurnal Variations in Precipitation and Thunderstorm Frequency over the Conterminous United States. Mon. Wea. Rev. 103, 406-419 (1975).

32. Balling, R. C. Jr. Warm season nocturnal precipitation in the Great Plains of the United States. J. Clim. Appl. Meteor. 24, 1383-1387 (1985).

33. Dai, A., Giorgi, F. \& Trenberth, K. E. Observed and model-simulated diurnal cycles of precipitation over the contiguous United States. J. Geophys. Res. 104, 6377-6402 (1999).

34. Carbone, R. E., Tuttle, J. D., Ahijevych, D. A. \& Trier, S. B. Inferences of predictability associated with warm season precipitation episodes. J. Atmos. Sci. 59, 2033-2056 (2002)

35. Jiang, X., Lau, N.-C. \& Klein, S. A. Role of eastward propagating convection systems in the diurnal cycle and seasonal mean of summertime rainfall over the U.S. Great Plains. Geophys. Res. Lett. 33, 2033-6 (2006).

36. Feng, Z. et al. More frequent intense and long-lived storms dominate the springtime trend in central US rainfall. Nat. Commun. 7, 511 (2016).

37. Surcel, M., Berenguer, M. \& Zawadzki, I. The diurnal cycle of precipitation from continental radar mosaics and numerical weather prediction models. Part I: methodology and seasonal comparison. Mon. Wea. Rev. 138, 3084-3106 (2010).

38. Qian, Y. et al. Parametric sensitivity analysis of precipitation at global and local scales in the Community Atmosphere Model CAM5. J. Adv. Modeling Earth Syst. 7, 382-411 (2015).

39. Wu, C.-M., Stevens, B. \& Arakawa, A. What controls the transition from shallow to deep convection? J. Atmos. Sci. 66, 1793-1806 (2009).
40. Crook, N. A. Sensitivity of moist convection forced by boundary layer processes to low-level thermodynamic fields. Mon. Wea. Rev. 124, 1767-1785 (1996).

41. Pielke, R. A. Influence of the spatial distribution of vegetation and soils on the prediction of cumulus convective rainfall. Rev. Geophysics 39, 151-177 (2001).

42. Yang, Z. et al. Impact of irrigation over the California central valley on regional climate. J. Hydrometeor. 18, 1341-1357 (2017).

43. Boucher, O., Myhre, G. \& Myhre, A. Direct human influence of irrigation on atmospheric water vapour and climate. Clim. Dyn. 22, 597-603 (2004).

44. Sacks, W. J., Cook, B. I., Buenning, N., Levis, S. \& Helkowski, J. H. Effects of global irrigation on the near-surface climate. Clim. Dyn. 33, 159-175 (2009).

45. Fritsch, J. M., Kane, R. J. \& Chelius, C. R. The contribution of mesoscale convective weather systems to the warm-season precipitation in the United States. J. Clim. Appl. Meteor. 25, 1333-1345 (1986).

46. Houze, R. A. Jr. 100 years of research on mesoscale convective systems. Meteorol. Monogr. 59(17), 1-17.54 (2018).

47. Gustafson, W. I. Jr, Ma, P.-L. \& Singh, B. Precipitation characteristics of CAM5 physics at mesoscale resolution during MC3E and the impact of convective timescale choice. J. Adv. Modeling Earth Syst. 6, 1271-1287 (2014).

48. Skamarock, W. C. et al. A description of the advanced research WRF version 3, NCAR Technical Note 1-113. https://doi.org/10.5065/D68S4MVH (2008).

49. Siebert, S. et al. Development and validation of the global map of irrigation areas Hydrol. Earth Syst. Sci. Discuss. 2, 1299-1327 (2005).

50. Smith, T. M. et al. Multi-radar multi-sensor (MRMS) severe weather and aviation products: initial operating capabilities. Bull. Am. Meteor. Soc. 97, 1617-1630 (2016).

51. Janowiak, J. E., Joyce, R. J. \& Yarosh, Y. A real-time global half-hourly pixel-resolution infrared dataset and its applications. Bull. Am. Meteor. Soc. 82, 205-217 (2001).

52. Lin, Y. GCIP/EOP Surface: Precipitation NCEP/EMC 4KM Gridded Data (GRIB) Stage IV Data. Version 1.0. https://doi.org/10.5065/D6PG1QDD (2011).

53. Taylor, K. E., Stouffer, R. J. \& Meehl, G. A. An overview of CMIP5 and the experiment design. Bull. Am. Meteor. Soc. 93, 485-498 (2012).

54. Willmott, C. J. \& Matsuura, K. Terrestrial Air Temperature and Precipitation: Monthly and Annual Time Series (1950-1999). (2001). Available at http://climate. geog.udel.edu/ climate/html_pages/README.ghcn_ts2.html (accessed 27 June 2019).

55. Thompson, G., Field, P. R., Rasmussen, R. M. \& Hall, W. D. Explicit forecasts of winter precipitation using an improved bulk microphysics scheme. Part II: implementation of a new snow parameterization. Mon. Wea. Rev. 136 5095-5115 (2008).

56. lacono, M. J. et al. Radiative forcing by long-lived greenhouse gases: Calculations with the AER radiative transfer models. J. Geophys. Res. Atmos. https://doi.org/ 10.1029/2008JD009944 (2008).

57. Nakanishi, M. \& Niino, H. An improved Mellor-Yamada level-3 model: its numerical stability and application to a regional prediction of advection fog. Bound. Layer. Meteorol. 119, 397-407 (2006).

58. Chen, F. et al. Modeling of land surface evaporation by four schemes and comparison with FIFE observations. J. Geophys. Res. Atmos. 101, 7251-7268 (1996)

\section{ACKNOWLEDGEMENTS}

This research was supported by the U.S. Department of Energy (DOE) Office of Science, Biological and Environmental Research as part of the Atmospheric Systems Research Program. The model simulations used resources from the National Energy Research Scientific Computing Center (NERSC), a U.S. Department of Energy Office of Science User Facility operated under Contract Number DE-AC02-05CH11231. Pacific Northwest National Laboratory is operated by DOE, by the Battelle Memorial Institute under contract DE-AC05-76RL01830. H.M. was funded by the Regional and Global Model Analysis Program Area (RGMA) and ASR Program of the U.S. DOE and his contribution was performed under the auspices of the U.S. DOE by Lawrence Livermore National Laboratory under contract DE-AC52-07NA27344.

\section{AUTHOR CONTRIBUTIONS}

Y.Q., Z.F., and Z.Y. developed the theory and Y.Q. wrote the first draft of manuscript. Y.L. conducted all simulations and some of analysis. Z.F. and Z.Y. performed some analysis and revised the manuscript. All authors contributed to the interpretation of the results and writing/revision to the final manuscript. 


\section{COMPETING INTERESTS}

The authors declare no competing interests.

\section{ADDITIONAL INFORMATION}

Supplementary information is available for this paper at https://doi.org/10.1038/ s41612-020-00135-w.

Correspondence and requests for materials should be addressed to Y.Q.

Reprints and permission information is available at http://www.nature.com/ reprints

Publisher's note Springer Nature remains neutral with regard to jurisdictional claims in published maps and institutional affiliations. (i) Open Access This article is licensed under a Creative Commons Attribution 4.0 International License, which permits use, sharing, adaptation, distribution and reproduction in any medium or format, as long as you give appropriate credit to the original author(s) and the source, provide a link to the Creative Commons license, and indicate if changes were made. The images or other third party material in this article are included in the article's Creative Commons license, unless indicated otherwise in a credit line to the material. If material is not included in the article's Creative Commons license and your intended use is not permitted by statutory regulation or exceeds the permitted use, you will need to obtain permission directly from the copyright holder. To view a copy of this license, visit http://creativecommons. org/licenses/by/4.0/.

This is a U.S. government work and not under copyright protection in the U.S.; foreign copyright protection may apply 2020 